\title{
Individual differences in multiple types of shifting attention
}

\author{
TOR D. WAGER \\ Columbia University, New York, New York \\ JOHN JONIDES \\ University of Michigan, Ann Arbor, Michigan \\ and \\ EDWARD E. SMITH \\ Columbia University, New York, New York
}

\begin{abstract}
Many researchers consider costs in shifting attention and mental set to reflect a basic ability to use top-down goal information to guide action. Although switch costs have been used as measures of individuals' executive function, whether common abilities underlie task set switching across different types of shifting tasks has not been well studied. In 249 participants, we studied whether switch costs in a novel two-choice reaction time task were correlated across variations in two variables: the locus of representation (stimuli were either perceptually available or stored in working memory [WM]) and which of two judgment tasks was performed. Switch costs were asymmetrical, in that it was easier to switch to the easier judgment, and were related to overall and relative processing speed: Switch costs were higher when the task was more difficult. These factors should be accounted for when one is measuring individual differences in switch costs. After controlling for these effects, we found evidence for a common ability underlying switch costs that involved both task set preparation and response selection; however, residual shift costs, which involve only response selection, were uncorrelated across tasks. Correlations among switch costs were substantially higher within task type (e.g., correlations of WM shifting tasks with other WM shifting tasks and of perceptual tasks with perceptual ones), suggesting that there are also processes unique to switching within WM and switching among visible stimuli.
\end{abstract}

A number of research articles in recent years have focused on the reaction time (RT) costs incurred when previously irrelevant information-generally, stimuli, stimulus attributes (dimensions), or responses - become relevant due to changing task demands (e.g., Garavan, 1998; Gopher, Armony, \& Greenshpan, 2000; Hsieh \& Allport, 1994; Meiran, Chorev, \& Sapir, 2000; Monsell, Yeung, \& Azuma, 2000; Rogers \& Monsell, 1995; Rubinstein, Meyer, \& Evans, 2001; Shafiullah \& Monsell, 1999; Yeung \& Monsell, 2003a). These are generally called task-switching paradigms, and they are thought to measure the ability to rapidly reconfigure perceptual and response sets to match changing environmental demands. Because a hallmark of such tasks is that they require flexible, context-dependent goal setting and execution, they

We thank James Steiger for providing the WBCORR software and Dr. Steiger and Jeremy Welland for extremely helpful advice and discussion on testing pattern hypotheses. Correspondence concerning this article should be addressed to T. D. Wager, Department of Psychology, Columbia University, 1190 Amsterdam Ave., New York, NY 10027 (e-mail: tor@psych.columbia.edu).

Note-This article was accepted by the previous editorial team, when Colin M. MacLeod was Editor. may be useful as measures of a fundamental type of cognitive control (e.g., Baddeley, 1992; Hitch \& Baddeley, 1976; Miller \& Cohen, 2001; Norman \& Shallice, 1986).

In a typical switching task, one is asked to respond to one of two or more attributes of a stimulus by making a speeded response. For instance, one might see the number/letter pair " $5 \mathrm{~A}$ " and be asked, on one trial, to judge whether the number is even or odd (Rogers \& Monsell, 1995). On the next trial, one may see a new stimulus (" 3 C") and be asked to make a vowel/consonant judgment on the letter (a switch trial) or to make the same odd/even judgment (a no-switch trial). The increase in average RT on switch trials, in comparison with no-switch trials, is the most common measure of switch costs.

Although the switching of attention demanded by these tasks is often referred to as an executive process (Garavan, Ross, Li, \& Stein, 2000; Gopher, 1996; Kimberg, Aguirre, \& D'Esposito, 2000; Miyake et al., 2000; Rubinstein et al., 2001; Sylvester et al., 2003), there has been debate about what types of mental processes switch costs reflect. According to one view, switch costs are likely to be related, at least in part, to the time it takes to retrieve previously inactive task rules and goals from long-term memory (Mayr \& Kliegl, 2000; Rogers \& Monsell, 1995; Spector \& Biederman, 1976). According to a second view, 
previously performed but currently irrelevant tasks continue to capture attention, prime task goals, or both, and switch costs reflect the time it takes to resolve interference from competing task sets (Allport, Styles, \& Hsieh, 1994). Whether observed switch costs are dominated by task set retrieval or interference resolution may depend largely on the particular demands of the task, including practice on switched-from and switched-to tasks (Wylie \& Allport, 2000; Yeung \& Monsell, 2003a, 2003b). However, both interference resolution time and task set recall time are subsumed under the general idea that switch costs reflect the time it takes to reconfigure processing biases on the basis of top-down goal information (Jersild, 1927; Rogers \& Monsell, 1995), with the recognition that not all tasks and stimuli are equally easy to switch among. Thus, although it is still unclear whether switching tasks are composed of multiple controlled retrieval, selective attention, and inhibitory processes, switching tasks are good candidates for core measures of the executive control of perception and action.

In this study, we were concerned with a fundamental property of task switch costs: the degree to which they reflect an underlying ability regardless of the type of switching task used. In most experimental studies, one task type has been used per experiment-for instance, switching between number and letter tasks (as in the example above), between odd/even and number magnitude, between global and local judgments, between attended objects or locations, or between several of these at once. These studies have varied the cue type (Coull, Frith, Büchel, \& Nobre, 2000), the target tasks (Allport et al., 1994; Rubinstein et al., 2001), and whether switching is among tasks themselves (i.e., both stimulus and response sets), operations (Spector \& Biederman, 1976), stimulus-response mapping rules (Rubinstein et al., 2001), objects stored in working memory (WM), object attributes (Owen, Roberts, Polkey, Sahakian, \& Robbins, 1991; Rogers \& Monsell, 1995), or combinations of these. Another class of switching tasks involve switching between counters maintained in WM (Garavan, 1998).

These are all referred to as studies of task switching or, sometimes, attention shifting, and theories have attempted to account for the phenomena discovered in these diverse tasks. However, the question of homogeneity across these tasks is critical if particular shifting tasks are used as measures of executive ability, or even if experimental findings are to be meaningfully integrated into a common theoretical framework. To what degree do these tasks reflect the same underlying core control processes, and to what degree do the executive control mechanisms engaged depend on the particular stimuli and processing demands of the task?

We used two strategies to address this question. The first was to assess whether patterns of switch costs would vary as a function of what was switched, the type of judgment required, and where information was represented (i.e., perceptually or in WM). The second was to examine how these variables would affect individual differences in switch costs.

\section{Individual Differences in Task Switching}

A potentially very informative way to provide information about whether different types of switch costs share common processes is to examine correlations among shift costs from various tasks. Stronger correlations are expected when two tasks share more common processing requirements, so the magnitudes of correlations among switch costs could be used to garner evidence about which types of switch costs reflect common abilities. However, to date, studies of individual differences in attention shifting appear to constitute a literature almost entirely separate from the one on experimental manipulations of switch costs. The individual-differences literature focuses on the concept of executive function and has, thus far, largely ignored differences among types of switching.

The idea that switching costs reflect executive control operations suggests that individuals who show low switch costs (efficient performance) may also show better performance on other tests of executive function. Perhaps the most direct test of this theory was conducted by Miyake et al. (2000). They used confirmatory factor analysis to identify performance scores on three putative measures of executive function - switching, inhibition, and monitoring information in $\mathrm{WM}$ - and related these factors to performance on commonly used neuropsychological tests thought to measure executive and frontal lobe function. They found that a latent factor of switching, with contributions from switch costs in three different tasks, was moderately related to other measures of executive function. The Wisconsin card sorting task, in particular, loaded most highly on the switching factor.

Other studies have concluded that putative tests of frontal lobe function share little in common (Burgess, Alderman, Evans, Emslie, \& Wilson, 1998; Duncan, Johnson, Swales, \& Freer, 1997; Rabbitt \& Lowe, 2000; Ward, Roberts, \& Phillips, 2001), raising the possibility that separate, more specific mechanisms underlie each task. Furthermore, the shared variance across executive function tasks may not be unique to executive function but, rather, may be shared with performance across a wide range of tasks (i.e., any task that loads high on Spearman's g; Duncan, Emslie, Williams, Johnson, \& Freer, 1996; Duncan et al., 1997; Rabbitt \& Lowe, 2000). An alternative view is that the attentional control capacity underlying executive working memory, basic processing speed, or both are core abilities underlying diverse types of performance (Bleckley, Durso, Crutchfield, Engle, \& Khanna, 2003; Conway, Kane, \& Engle, 2003; Kane et al., 2004; Salthouse, 1996; Salthouse, Fristoe, McGuthry, \& Hambrick, 1998). Salthouse et al. found that an identifiable task-switching construct was dissociable from processing speed and was related to performance on an episodic memory task. However, all of Salthouse et al.'s switching tasks involved similar stimuli and tasks - switching between odd/even and magnitude judgments on single-digit numerals - so the representativeness of performance on these tasks of a general switching ability could not be assessed. In fact, none of the studies mentioned above assessed whether switching could be fractionated into separate types. 


\section{The Present Study}

In the present experiment, we measured eight types of switch costs that varied on three variables. The first was the perceptual availability of stimuli, or the locus of representation. On some trials, the participants switched between visible stimuli (e.g., external locus of representation), and on other trials, the participants switched between stimuli stored in WM (internal locus). A second variable was what was switched between: The participants switched between whole objects, attributes of objects (i.e., dimensions in some articles; cf. Owen et al., 1991; Roberts \& Wallis, 2000), both, or neither. Two attributes were judged: object shape and object orientation. For external and internal object and attribute switching, we measured separate switch costs for shape and orientation judgments.

The question of interest was whether switch costs for shape and orientation judgments would be comparable for external and internal object and attribute switching tasks. Thus, we focused on comparing both magnitudes of switch costs and correlations in switch costs within and across external and internal loci and across shape and orientation judgments. We were particularly interested in whether correlations across varying loci and judgment types would be correlated at all and whether holding each variable constant would substantially increase correlations among switch costs. These comparisons were made for both object switches and attribute switches.

We chose these types of tasks (internal and external, object and attribute) because they are commonly used in switching tasks, but an analysis of the importance of variations in these types has not been performed. The classic switching paradigm of Rogers and Monsell (1995), for example, involves simultaneous switching between objects (number or letter) and attributes of those objects (the odd/ even status or the vowel/consonant status) represented in an external locus (stimuli are onscreen), but this task is widely considered to be representative of task switching generally. Likewise, we chose to study internal and external loci because there are separate literatures on each type of switch, although they are often assumed to reflect comparable taskswitching processes; however, because one type involves perception and the other relies on working memory, we reasoned that there might well be separate mechanisms for shifting in each of these domains. In support of this view, an fMRI study in which the same paradigm was used as that employed here showed a double dissociation between switching costs in external and internal loci, with the former producing greater event-related switching activation in the bilateral extrastriate cortex and the latter producing greater activation in the left frontal cortex and the intraparietal sulcus (Wager, Jonides, Smith, \& Nichols, 2005).

Another important variable in switching tasks is whether the goal of responding to one particular attribute can be prepared in advance (e.g., Rogers \& Monsell, 1995). There is substantial evidence that switch costs can be reduced, but not eliminated, by cuing which task is to be performed before presenting the stimulus on which judgments are to be made (e.g., Mayr, 2003; Mayr \& Kliegl, 2000; Meiran, 1996; Rogers \& Monsell, 1995). The costs remaining after long preparation intervals are residual switch costs. On the basis of this evidence, current theory suggests that goal shifting (or endogenous task set engagement) and rule activation are distinct stages of processing (Rubinstein et al., 2001). The first involves retrieval of task goals (e.g., judge the shape) on the basis of cue information, and the second involves selection and application of mapping rules (e.g., rectangle $=$ left response, ellipse $=$ right response), which at least partially requires the presentation of the imperative stimulus.

One type of switching in our study involved no precuing of task, and so switch costs reflected both stages of processing. A second type was divided into preparatory readiness times and residual switch costs. Thus, we could examine whether the patterns we observed applied both to switch costs that involve goal shifting and to residual switch costs.

\section{METHOD}

\section{Participants}

The participants were 268 adults $18-40$ years of age, recruited from the Ann Arbor area. The study was reviewed and approved by the University of Michigan human participants Institutional Review Board. To be included in the analysis, the participants were required to be at least $80 \%$ accurate on all types of switch and nonswitch trials (14 participants were excluded), and 5 participants were excluded as multivariate outliers, due to an unusual pattern of RT data across conditions (Johnson \& Wichern, 2002), leaving a final sample for analysis of $N=249$.

The participants were paid $\$ 8 / \mathrm{h}$ for participation, in addition to a performance bonus calculated on both speed and accuracy. Bonus feedback was given after blocks of 48 trials, with 5 cents awarded per correct trial only if the participants' mean RT was shorter than that on the previous block. To receive the bonus on the first block, the participants had to be faster than $1,000 \mathrm{msec}$, on average. Total bonus values ranged from approximately $\$ 3$ to $\$ 12$.

\section{Task Design}

The task consisted of multipart trials, each requiring two judgments about the same stimulus. The stimuli were images of two overlapping objects, one red and one blue, as shown in the first panel of Figure 1A. The color served as a cue for which object to attend. Each object was either an ellipse or a rectangle (two rectangles or two ellipses were allowed). One object was always oriented vertically, and the other horizontally.

On each self-paced trial, the objects appeared during an initial encoding phase, during which the participants were instructed to focus on the stimulus and prepare for the trial. When the participants pressed the space bar, a cue appeared above the shapes with the words, "attend red" or "attend blue," which signaled the participants to attend to the corresponding shape (orient phase). Upon another space bar press, a judgment was required (J1 phase): Either the words "judge shape" or "judge orientation" appeared. If shape judgment was indicated, the participants pressed with the right index finger if the attended shape was an ellipse or with the right middle finger if it was a rectangle. If an orientation judgment was indicated, the participants pressed with the right index finger if the attended shape was vertical or with the right middle finger if it was horizontal.

Following the buttonpress and an additional 200-msec delay (inserted after each of the remaining phases of the trial), the words "switch object" or "same object" appeared on the screen, indicating whether the participant was to shift attention to the unattended object or remain on the same object (object cue phase). The participants were instructed to press the space bar when they completed the shift of attention. After the response and a 200-msec delay, the participants were asked to either "judge shape" or "judge orientation" again (J2 phase). The task performed in $\mathrm{J} 2$ was the judgment type variable in the analysis. 
A Attribute Switch (If Different)

External Trial

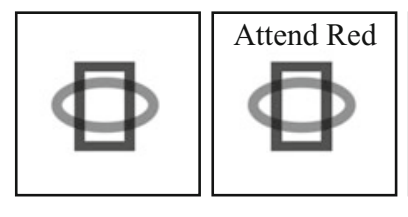

B

Internal Trial

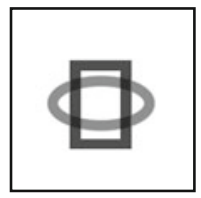

C Encode

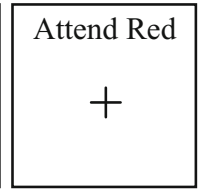

Orient
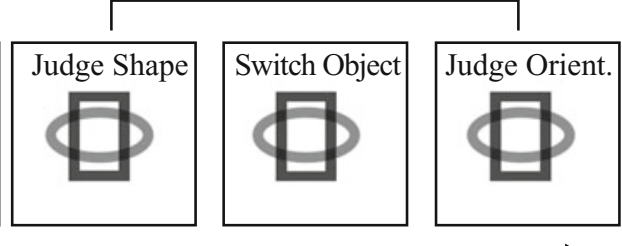

Time

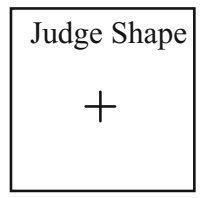

Judge 1 (J1)

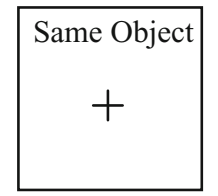

Object

Switch Cue

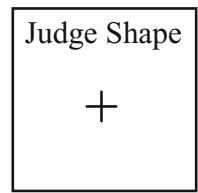

Judge 2 (J2)

Figure 1. Example trials from the task design (not drawn to scale). The panels illustrate successive events within the trial. In the actual experiment, the objects were colored blue (darker shading) and red (lighter shading). The eight different configurations of red and blue ellipses and rectangles in vertical and horizontal orientations were used in equal numbers, with a new stimulus configuration appearing on each trial. (A) On external trials, the stimulus was visible continuously, as is depicted here. (B) On internal trials, the stimulus was visible only in the first panel, and language cues appeared in the center of the screen. (C) The names of each phase of the trial are printed below the panels. Object switching reaction time (RT) costs in the object cue phase were calculated as RT for switch - stay trials. Trials were attribute switches if the attribute during the second judgment $(\mathrm{J} 2)$ phase did not match that of the first judgment. In J2, RT measures were collected for each trial type (switch attribute and object, switch object only, switch attribute only, or no switch).

The switch variable. Attribute switch trials were ones on which the relevant attribute (shape or orientation) for the second judgment was different from that for the first judgment of the trial. The critical RT measure for this was during the second judgment period for switch and nonswitch trials. Object switch trials were ones on which the participant was asked to shift between objects, and two RT measures for this shift were collected: time to respond to the switch cue "same" versus "switch" and time to respond during the second judgment. Previous research has shown that even given quite a long time to prepare for an upcoming switch trial, responses to targets are still slower on switch than on no-switch trials (e.g., Meiran et al., 2000; Monsell et al., 2000; Rogers \& Monsell, 1995).

The locus of representation variable. On external trials (Figure $1 \mathrm{~A}$ ), the stimulus remained on the screen throughout the trial, and cues appeared just above the stimulus. On internal trials (Figure $1 \mathrm{~B}$ ), the stimulus was present only for the initial viewing period, so that it was necessary to refer to a representation of the object in WM to complete the trial. When the words "attend red" (or blue) appeared, the shape disappeared for the rest of the trial. Blocks of 48 external (E) and internal (I) trials were alternately performed (E I E I E I), with two blocks of practice preceding test blocks. Trials were arranged in a fixed, prerandomized order, to minimize order effects on individual differences (e.g., Miyake et al., 2000).

\section{Data Analysis}

Mean RTs for correct trials in each condition were calculated for each participant after removing outliers greater than three standard deviations from the mean of the condition within participants (Kane \& Engle, 2003) This procedure was chosen because it produced the highest overall split-half (odd/even trial) reliabilities and test-retest reliabilities for switching costs, in comparison with more extensive trimming procedures (Rousseeuw, 1984) and log transformation.
We will report two kinds of analyses: (1) examination of the magnitude of switch costs and how they interact with judgment type and locus of representation, tested using an ANOVA, and (2) pattern hypothesis tests on correlations among switch costs of different types, after controlling for overall and relative processing speed.

In the ANOVA, the four switch type variables were object switch status (switch vs. no switch), attribute switch status (switch vs. no switch), locus of representation (external vs. internal), and judgment type (shape vs. orientation). Mean RTs and accuracies were analyzed for the effects of each of these variables in a $2 \times 2 \times 2 \times 2$ factorial repeated measures ANOVA design. However, because of the large number of main effects and interactions, we will present results from a priori hypotheses focused on whether switch costs and individual differences in switch costs vary by locus and judgment type. These hypotheses concerned attribute and object switch costs during J2 and object switch costs during the object cue period. Means for each trial type and an explanation of how switch costs were estimated across types are provided in Table 2 . To avoid additional interactions with response compatibility, ANOVAs were restricted to incompatible trials - that is, those on which the responses to the relevant attribute of both objects were different. Otherwise, switch costs and correlations among switch costs could be driven by interference effects on incompatible trials. Although previous studies have usually shown these to be additive with switch costs, our goal was to examine switching without this additional complicating variable. Analyses on $\log$ RTs produced qualitatively identical results.

\section{RESULTS AND DISCUSSION}

\section{Behavioral Data: RT and Accuracy ANOVAs}

Main effects of locus of representation and judgment type. We will first describe main effects of task type 
variables for each period of the trial, followed by a description of switch costs and switch cost asymmetries.

J1 period. Processing speed for each task type (Table 1) provides information about the ease (or strength of automaticity) of the tasks. A main effect of locus on RT $\left[F(1,248)=88, M S_{\mathrm{e}}=134,000, p<.001\right]$ and accuracy $\left[F(1,248)=63, M S_{\mathrm{e}}=0.00255, p<.001\right]$ showed that, surprisingly, responses were slower and less accurate in the external than in the internal condition (WM) (126 msec, .012 difference in proportion correct). This slowing may reflect interference associated with visible cues or the greater accessibility of stimuli that are already in WM. We also note that $\mathrm{J} 1$ times are longer than J2 times, which could reflect time spent orienting toward the judgment tasks at the beginning of the trials or priming of the judgment tasks after J1. These effects were not of primary interest, since we were concerned with switch costs during $\mathrm{J} 2$.

Analyses of judgment type (shape vs. orientation judgments) showed a main effect on $\mathrm{RT}\left[F(1,248)=68, M S_{\mathrm{e}}=\right.$ $171,000, p<.001]$, but not on accuracy. Shape judgments were faster than orientation judgments $(101 \mathrm{msec})$, and these results paralleled our subjective impressions that shape was a more salient feature of the stimuli. Since orientation judgments were slower and slowness is one indicator of relative salience or automaticity of processing, these results suggest that orientation judgments are the "weaker" task. There was no locus $\times$ judgment type interaction.
Object cue period. The RT data, presented in Table 2, showed a main effect of locus $\left[F(1,248)=39, M S_{\mathrm{e}}=\right.$ $132,000, p<.001]$. External judgments were slower (by $80 \mathrm{msec}$ ). There was no main effect of judgment type. Accuracy data were not collected for this period.

$J 2$ period. As before, we observed main effects of judgment type $\left[F(1,248)=150, M S_{\mathrm{e}}=137,000, p<.001\right.$; see Table 2] and locus $\left[F(1,248)=118, M S_{\mathrm{e}}=111,000\right.$, $p<.001]$. Shape judgments were faster than orientation judgments (by $143 \mathrm{msec}$ ), and internal judgments in WM were faster than external perceptual judgments (by $115 \mathrm{msec}$ ). There was no locus of representation $\times$ judgment type interaction. Accuracy effects were significant for locus $\left[F(1,248)=25.18, M S_{\mathrm{e}}=0.0138, p<.001\right]$, indicating that internal judgments were more accurate, but not for judgment type. The speed-accuracy trade-off suggests that neither external nor internal tasks were clearly easier in $\mathrm{J} 2$.

Object and attribute shifting costs. Our results for each of the periods were as follows.

$J 1$ period. Switch costs in J1 performance were not expected in the present analyses, since this period occurred before the presentation of cues to shift or maintain attention. As was expected, neither main effects of object switch status nor attribute switch status were significant for either RT or accuracy, even with this large sample $(N=249)$. The observed trends are over an order of magnitude smaller than the switch costs observed during $\mathrm{J} 2$. Because we used a fixed, prerandomized trial order that did not vary across

Table 1

Mean Reaction Times (RTs, in Milliseconds) and Accuracy (Proportion Correct) for Each Trial Type in the First Judgment Period (J1) (With Standard Errors)

\begin{tabular}{|c|c|c|c|c|c|c|c|c|}
\hline \multirow[b]{3}{*}{ Type } & \multirow[b]{3}{*}{$\mathrm{J} 1$} & \multirow[b]{3}{*}{ Cue } & \multirow[b]{3}{*}{$\mathrm{J} 2$} & \multirow[b]{3}{*}{ Sw. Type } & \multicolumn{4}{|c|}{$\mathrm{J} 1$} \\
\hline & & & & & \multicolumn{2}{|c|}{ RT } & \multicolumn{2}{|c|}{ Accuracy } \\
\hline & & & & & $M$ & $S E$ & $M$ & $S E$ \\
\hline \multicolumn{9}{|c|}{ External Switches } \\
\hline $\mathrm{A}$ & Shape (O1) & Stay & Shape (O1) & None & 1,186 & 40.2 & .973 & .005 \\
\hline B & Orientation $(\mathrm{O} 1)$ & Stay & Orientation $(\mathrm{O} 1)$ & None & 1,242 & 42.1 & .986 & .003 \\
\hline $\mathrm{C}$ & Orientation $(\mathrm{O} 1)$ & Stay & Shape (O1) & Att & 1,294 & 38.6 & .979 & .003 \\
\hline $\mathrm{D}$ & Shape (O1) & Stay & Orientation $(\mathrm{O} 1)$ & Att & 1,352 & 39.8 & .979 & .004 \\
\hline $\mathrm{E}$ & Shape (O1) & Switch & Shape (O2) & Obj & 1,278 & 43.6 & .977 & .004 \\
\hline $\mathrm{F}$ & Orientation $(\mathrm{O} 1)$ & Switch & Orientation $\left(\mathrm{O}_{2}\right)$ & $\mathrm{Obj}$ & 1,334 & 44.1 & .980 & .003 \\
\hline G & Orientation (O1) & Switch & Shape (O2) & $\mathrm{Dbl}$ & 1,303 & 46.5 & .985 & .003 \\
\hline $\mathrm{H}$ & Shape (O1) & Switch & Orientation $(\mathrm{O} 2)$ & Dbl & 1,212 & 40.3 & .976 & .004 \\
\hline \multicolumn{9}{|c|}{ Internal Switches } \\
\hline A & Shape (O1) & Stay & Shape (O1) & None & 1,154 & 34.9 & .953 & .006 \\
\hline B & Orientation $(\mathrm{O} 1)$ & Stay & Orientation $(\mathrm{O} 1)$ & None & 1,160 & 39.1 & .966 & .006 \\
\hline $\mathrm{C}$ & Orientation (O1) & Stay & Shape $(\mathrm{O} 1)$ & Att & 1,134 & 34.9 & .951 & .005 \\
\hline $\mathrm{D}$ & Shape $(\mathrm{O} 1)$ & Stay & Orientation $(\mathrm{O} 1)$ & Att & 1,116 & 35.4 & .977 & .004 \\
\hline E & Shape (O1) & Switch & Shape (O2) & Obj & 1,081 & 36.0 & .952 & .007 \\
\hline $\mathrm{F}$ & Orientation $(\mathrm{O} 1)$ & Switch & Orientation $(\mathrm{O} 2)$ & $\mathrm{Obj}$ & 1,174 & 36.3 & .967 & .004 \\
\hline $\mathrm{G}$ & Orientation (O1) & Switch & Shape (O2) & $\mathrm{Dbl}$ & 1,164 & 46.8 & .965 & .005 \\
\hline $\mathrm{H}$ & Shape (O1) & Switch & Orientation $(\mathrm{O} 2)$ & Dbl & 994 & 34.0 & .967 & .005 \\
\hline
\end{tabular}

Note-No switch costs were expected in J1. Judgments were made on object shape or orientation. O1 indicates response to the initially cued object, cued by color (red or blue). $\mathrm{O} 2$ indicates response to the initially uncued object. Cue, object switch cue period; Switch indicates a cue to shift to the unattended object, and Stay indicates a cue to sustain attention on the same object. J2, second judgment period. Sw. Type, task switch type (None for no switch, Att for attribute switch only, Obj for object switch only, Dbl for double attribute-object switch). 
Table 2

Mean Reaction Times (RTs, in Milliseconds) for Object Switch Cue Period and Mean RTs and Accuracy (Proportion Correct) for Second Judgment (J2) Period (With Standard Errors)

\begin{tabular}{|c|c|c|c|c|c|c|c|c|c|c|}
\hline \multirow[b]{3}{*}{ Type } & \multirow[b]{3}{*}{$\mathrm{J} 1$} & \multirow[b]{3}{*}{ Cue } & \multirow[b]{3}{*}{$\mathrm{J} 2$} & \multirow[b]{3}{*}{ Sw. Type } & & & \multicolumn{4}{|c|}{$\mathrm{J} 2$} \\
\hline & & & & & \multicolumn{2}{|c|}{ Object Cue RT } & \multicolumn{2}{|c|}{ RT } & \multicolumn{2}{|c|}{ Accuracy } \\
\hline & & & & & $M$ & $S E$ & $M$ & $S E$ & $M$ & $S E$ \\
\hline \multicolumn{11}{|c|}{ External Switches } \\
\hline A & Shape (O1) & Stay & Shape (O1) & None & 820 & 27.0 & 990 & 31.3 & .975 & .005 \\
\hline $\mathrm{B}$ & Orientation (O1) & Stay & Orientation $(\mathrm{O} 1)$ & None & 860 & 31.3 & 1,036 & 36.0 & .978 & .003 \\
\hline $\mathrm{C}$ & Orientation (O1) & Stay & Shape (O1) & Att & 875 & 28.5 & 1,141 & 39.7 & .948 & .006 \\
\hline $\mathrm{D}$ & Shape (O1) & Stay & Orientation $(\mathrm{O} 1)$ & Att & 928 & 37.0 & 1,241 & 40.0 & .955 & .006 \\
\hline $\mathrm{E}$ & Shape (O1) & Switch & Shape (O2) & Obj & 1,003 & 46.0 & 1,142 & 37.2 & .944 & .008 \\
\hline $\mathrm{F}$ & Orientation $(\mathrm{O} 1)$ & Switch & Orientation $(\mathrm{O} 2)$ & Obj & 1,077 & 61.4 & 1,224 & 40.9 & .952 & .007 \\
\hline G & Orientation $(\mathrm{O} 1)$ & Switch & Shape $(\mathrm{O} 2)$ & $\mathrm{Dbl}$ & 1,012 & 54.9 & 1,443 & 45.1 & .943 & .007 \\
\hline $\mathrm{H}$ & Shape (O1) & Switch & Orientation $(\mathrm{O} 2)$ & $\mathrm{Dbl}$ & 967 & 55.5 & 1,286 & 36.5 & .900 & .008 \\
\hline \multicolumn{11}{|c|}{ Internal Switches } \\
\hline A & Shape (O1) & Stay & Shape (O1) & None & 751 & 23.7 & 911 & 40.7 & .958 & .006 \\
\hline $\mathrm{B}$ & Orientation $(\mathrm{O} 1)$ & Stay & Orientation $(\mathrm{O} 1)$ & None & 789 & 24.2 & 924 & 31.7 & .967 & .006 \\
\hline $\mathrm{C}$ & Orientation $(\mathrm{O} 1)$ & Stay & Shape $(\mathrm{O} 1)$ & Att & 785 & 25.4 & 1,058 & 34.9 & .949 & .007 \\
\hline $\mathrm{D}$ & Shape (O1) & Stay & Orientation $(\mathrm{O} 1)$ & Att & 780 & 31.2 & 1,168 & 41.3 & .923 & .008 \\
\hline $\mathrm{E}$ & Shape (O1) & Switch & Shape $(\mathrm{O} 2)$ & Obj & 907 & 42.0 & 1,002 & 31.5 & .939 & .007 \\
\hline $\mathrm{F}$ & Orientation $(\mathrm{O} 1)$ & Switch & Orientation $(\mathrm{O} 2)$ & $\mathrm{Obj}$ & 897 & 40.3 & 995 & 30.9 & .950 & .006 \\
\hline G & Orientation (O1) & Switch & Shape $(\mathrm{O} 2)$ & $\mathrm{Dbl}$ & 962 & 56.6 & 1,478 & 63.1 & .879 & .010 \\
\hline $\mathrm{H}$ & Shape $(\mathrm{O} 1)$ & Switch & Orientation $(\mathrm{O} 2)$ & Dbl & 868 & 41.8 & 1,191 & 43.3 & .872 & .009 \\
\hline
\end{tabular}

Note-J1, first judgment period. O1 indicates response to the initially cued object, cued by color (red or blue). O2 indicates response to the initially uncued object. Sw. Type, task switch type (none for no switch, Att for attribute switch only, Obj for object switch only, Dbl for double attribute-object switch). Switch indicates a cue to shift to the unattended object, and Stay indicates a cue to sustain attention on the same object. Object switch costs were defined as $\mathrm{ABCD}-\mathrm{EFGH}$, where $\mathrm{ABCD}$ indicates averaged performance across Conditions A-D. Attribute switch costs were defined as $\mathrm{CDGH}-\mathrm{ABEF}$. The interaction between switch costs was defined as ABGH - CDEF. Asymmetries in switch costs in J2 were defined as orientation - shape switch costs: $(\mathrm{DH}-\mathrm{FB})-(\mathrm{EG}-\mathrm{AC})$ for attribute switches and $(\mathrm{FH}-\mathrm{BD})-(\mathrm{EG}-\mathrm{AC})$ for object switches. Object switch costs were expected during the cue period, and both attribute and object switch costs were expected during $\mathrm{J} 2$.

participants, some small differences in $\mathrm{J} 1$ cell means were expected, due to trial history effects and imperfect random assignment of each of the eight stimulus types and two initial color cues across trial types. These effects proved to be appreciable in the present study, since the mean RTs differed across trial types involving the same initial judgment. However, these effects do not impact the switch costs of interest, since no significant differences in $\mathrm{J} 1$ activity as a function of later switching demands were found.

Object cue period. We tested for object switch costs during this period, which would indicate that the participants took longer to prepare when the cue indicated an object switch. Such costs are similar to the readiness times of Meiran, Hommel, Bibi, and Lev (2002), and they are likely to reflect both the time required to reconfigure attentional focus to the unattended object and strategic choices about how completely participants shift attention before they are willing to proceed. We observed a main effect of object switch status $\left[F(1,248)=47, M S_{\mathrm{e}}=225,000, p<.001\right]$, but not of attribute switch status, as was expected (see Table 3). Object switches were $121 \mathrm{msec}$ slower than nonswitches. There was no significant locus $\times$ object switch interaction.

$J 2$ period. This was the critical period in which we expected both attribute and object shift costs, although object shift costs are residual costs after preparation in the cue period is completed. Here, we will discuss whether shift costs differed for internal and external loci. Subsequently, we will discuss whether these shift costs were similar across judgment types (i.e., switch cost asymme- tries in switches to shape vs. orientation judgments). Figure 2 shows mean RTs and error rates during $\mathrm{J} 2$ for all the conditions, and switch costs are reported in Table 3 .

We observed main effects of both attribute switching $\left[F(1,248)=264, M S_{\mathrm{e}}=143,000, p<.001 ; 194 \mathrm{msec}\right]$ and object switching $\left[F(1,248)=251, M S_{\mathrm{e}}=88,300\right.$, $p<.001 ; 149 \mathrm{msec}]$. Both switch costs were observed in accuracy as well $\left[F(1,248)=198, M S_{\mathrm{e}}=0.00461, p<\right.$ .0001 for attribute switching (a .0303 decrement), and $F(1,248)=113, M S_{\mathrm{e}}=0.00471, p<.0001$, for object switching (a 0.0232 decrement)], as is shown in the right panel of Figure 2 and in Table 3.

Attribute switch status showed a trend toward interaction with locus $\left[F(1,248)=2.94, M S_{\mathrm{e}}=253,000, p=.08\right]$, with RT switch costs of 179 and $211 \mathrm{msec}$ for external and internal loci, respectively. Object switch status showed an interaction with locus $\left[F(1,248)=10.80, M S_{\mathrm{e}}=89,000\right.$, $p<.001]$, with switch costs of 180 and $118 \mathrm{msec}$ for external and internal loci, respectively. Switch status $\times$ locus interactions were observed in accuracy as well: For attribute switch status, $F(1,248)=24.80, M S_{\mathrm{e}}=0.00373$, $p<.001$, with larger switch costs for internal (.0400 cost) than for external $(.0207$ cost) loci; for object switch status, $F(1,248)=4.14, M S_{\mathrm{e}}=0.00373, p<.05$, with larger object switch costs for internal $(0.0275$ cost $)$ than for external $(0.0190$ cost $)$ loci, although this effect was much less reliable than most of the effects observed in this study.

These interactions show that attribute switching was substantially more costly on internal representations, 
whereas object-switching costs showed a speed-accuracy trade-off (Pachella, 1974), with large RT cost differences for external versus internal locus and a small accuracy cost difference for internal versus external locus. Overall, object switches were more difficult in the external locus, and attribute switches were more difficult in the internal locus. This suggests that internal and external shifting demand some different capacities.

If object and attribute shifting are performed serially, one might expect additive effects of object and attribute shifting on J2 RT and accuracy. However, we found a small but significant object switch status $\times$ attribute switch status interaction in RT $\left[F(1,248)=6.15, M S_{\mathrm{e}}=69,800\right.$, $p<.05]$, which indicated that dual switches took longer than the sum of single switch costs (by $21 \mathrm{msec}$ ). In accuracy, the effect was stronger $\left[F(1,248)=7.56, M S_{\mathrm{e}}=\right.$ $0.00364, p<.01]$, with a dual-switch accuracy cost of .0052 . Object switch status $\times$ attribute switch status $\times$ locus interactions were assessed to test whether dualswitch costs were similar for external and internal loci. This interaction showed a trend in the RT data $[F(1,248)=$ $\left.3.54, M S_{\mathrm{e}}=79,900, p=.06\right]$, with larger object $\times$ attribute switch interactions for internal $(38 \mathrm{msec})$ than for external $(4 \mathrm{msec})$ loci. The accuracy data showed the same effect $\left[F(1,248)=8.33, M S_{\mathrm{e}}=0.00340, p<.01\right]$, with larger object $\times$ attribute switch interactions for internal (.0106) than for external (.0001) loci. Thus, there was evidence for overadditive costs of dual switches in internal tasks but almost perfectly additive effects in external loci, providing evidence that switching between stimuli that are visible versus those stored in WM involves different processes.

Switch cost asymmetries (judgment type $\times$ object/ attribute switch). We examined asymmetries in switch costs in $\mathrm{J} 2$ depending on judgment type, to test whether switch costs were similar across shape and orientation
Table 3

Switching Costs in Reaction Times (RTs, in Milliseconds) and Accuracy Calculated as Main Effects (With Standard Errors), and Reliability

\begin{tabular}{|c|c|c|c|c|c|}
\hline \multirow[b]{2}{*}{ Switch Type } & \multicolumn{2}{|c|}{ RT } & \multicolumn{2}{|c|}{ Accuracy } & \multirow[b]{2}{*}{ Reliability } \\
\hline & Effect & $S E$ & Effect & $S E$ & \\
\hline \multicolumn{6}{|l|}{ External Shape Task (shE) } \\
\hline Object switch (cue) & 69 & 24 & - & - & .91 \\
\hline Object switch (J2) & 138 & 15 & -0.45 & 0.39 & .63 \\
\hline Attribute switch (J2) & 134 & 16 & -1.26 & 0.39 & .82 \\
\hline Object $*$ attribute $(\mathrm{J} 2)$ & 22 & 14 & 1.19 & 0.37 & .41 \\
\hline \multicolumn{6}{|l|}{ Internal Shape Task (shI) } \\
\hline Object switch (cue) & 141 & 23 & - & - & .86 \\
\hline Object switch (J2) & 103 & 16 & -2.45 & 0.42 & .51 \\
\hline Attribute switch (J2) & 153 & 16 & -3.56 & 0.43 & .61 \\
\hline Object $*$ attribute $(\mathrm{J} 2)$ & 20 & 16 & -1.02 & 0.38 & .35 \\
\hline \multicolumn{6}{|c|}{ External Orientation Task (orE) } \\
\hline Object switch (cue) & 176 & 25 & - & - & .91 \\
\hline Object switch (J2) & 222 & 23 & -3.35 & 0.46 & .63 \\
\hline Attribute switch (J2) & 223 & 22 & -2.88 & 0.36 & .82 \\
\hline Object $*$ attribute $(\mathrm{J} 2)$ & -14 & 21 & -1.17 & 0.34 & .41 \\
\hline \multicolumn{6}{|c|}{ Internal Orientation Task (orI) } \\
\hline Object switch (cue) & 100 & 21 & - & - & .86 \\
\hline Object switch (J2) & 133 & 19 & -3.04 & 0.44 & .51 \\
\hline Attribute switch (J2) & 268 & 24 & -4.43 & 0.50 & .61 \\
\hline Object $*$ attribute $(\mathrm{J} 2)$ & 56 & 18 & -1.10 & 0.44 & .35 \\
\hline Overall (judgment period) & 1,215 & 28 & 94.18 & 0.29 & .99 \\
\hline
\end{tabular}

Note-Positive values in RTs indicate that responses on switch trials were slower than those on nonswitch trials. Positive interaction values indicate that double-switch trials showed an RT cost greater than the sum of switch costs for single switches. Negative values for accuracy indicate switch costs in accuracy. Reliability, odd/even split-half reliability, adjusted using the Spearman-Brown prophecy formula, computed collapsing across shape and orientation judgments.

judgment tasks. Differences in attribute switching by judgment type are asymmetries in task switch costs, which reflect the difference in switch costs when there are shifts from orientation to shape (referred to in Tables 4-6 as sh), in comparison with shifts from shape to orientation (re-
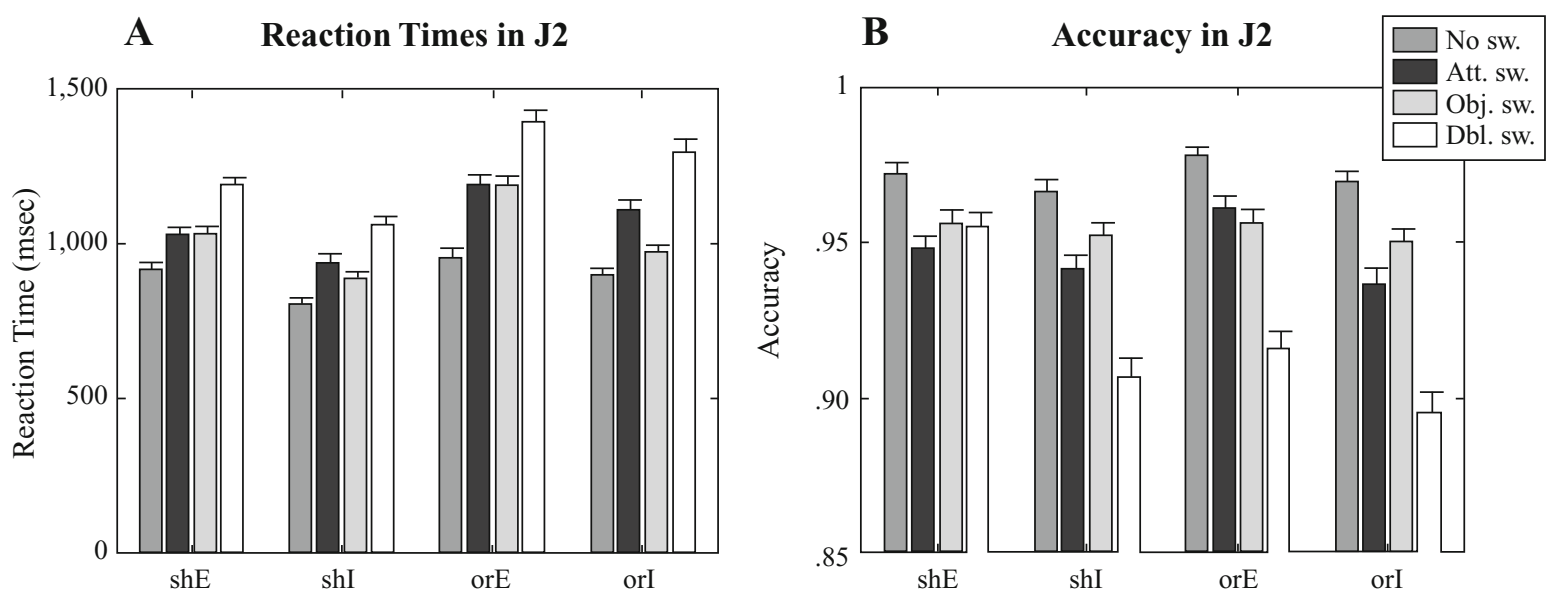

Figure 2. Behavioral performance data. (A) Reaction times (RTs) for each condition during the second judgment (J2) period (the critical phase of the trial). I, internal locus; E, external locus; sh, shape judgment; or, orientation judgment. For example, shI columns show RTs for shape judgments preceded by shape judgments (for no-attribute-switch conditions) or orientation judgments (for attribute switch judgments) for the internal locus. (B) Accuracy by condition (proportions). Error bars show standard errors of the means. No sw., no switch; Att. sw., attribute switch; Obj. sw., object switch; Dbl. sw., double switch. 
ferred to as or). Some previous work has shown that it is easier to switch to the "weaker" (slower) task (Allport et al., 1994; Monsell et al., 2000), but other studies have shown the reverse (Monsell et al., 2000). The difference is thought to be a function of how much the strong task can interfere with the weak one (Yeung \& Monsell, 2003). With much interference, the strong task may be actively suppressed when the weaker task is performed, causing greater difficulty in switching to the stronger task. For object shifts, effects of judgment type reflect asymmetries in shifting from object to object on the stronger task (shape, in the present experiment), in comparison with the weaker one (orientation). Asymmetries between switch costs were assessed by judgment type $\times$ switch status interactions.

Effects of judgment type on switch costs provide some support for the idea that cognitive processes may be differentially engaged in switching between strong and weak tasks (for attribute switches) or in switching between objects, depending on the ease of the task (for object switches). One example of a process that may be more strongly engaged with harder tasks may be task set retrieval from long-term memory (Dreher, Koechlin, Ali, \& Grafman, 2002; Mayr \& Kliegl, 2000), which may be more difficult for weaker tasks, particularly if the stimulus serves as a cue for task set retrieval (Koch, 2003; Wylie \& Allport, 2000). Here, we tested for asymmetries in overall switch costs. Below, we will provide more direct tests of the similarity of switching on stronger (shape) and weaker (orientation) tasks with correlation analyses.

The judgment type $\times$ object switch status effect was significant for RT and accuracy [for RT, $F(1,248)=4.56$, $M S_{\mathrm{e}}=50,300, p<.05$; for accuracy, $F(1,248)=14.90$, $\left.M S_{\mathrm{e}}=0.00505, p<.001\right]$. Object switch costs were higher when orientation was judged (177 msec, .0290 accuracy costs) than when shape was judged (121 msec, .0145 accuracy costs). Thus, it is easier to switch among objects when the task is easier.

The judgment type $\times$ attribute switch status was significant for RT and accuracy [for RT, $F(1,248)=31$, $M S_{\mathrm{e}}=82,500, p<.001$; for accuracy, $F(1,248)=7.59$, $\left.M S_{\mathrm{e}}=0.00509, p<.01\right]$. Attribute switch costs were higher when there was a switch from shape to orientation (245 msec, .0322 accuracy costs) than when there was one from orientation to shape (144 msec, .0241 costs). Thus, it was more difficult to shift to (and easier to shift away from) the weaker orientation judgment task.

Object switch cost asymmetries were similar for external and internal loci, as was suggested by a nonsignificant locus $\times$ judgment type $\times$ object switch status interaction. However, in accuracy, there was a significant interaction $\left[F(1,248)=8.12, M S_{\mathrm{e}}=0.00409, p<.01\right]$, indicating that asymmetries were greater for external (.0029 accuracy asymmetry) than for internal (.0059 asymmetry) loci. The locus $\times$ judgment type $\times$ attribute switch status interaction was not significant in either RT or accuracy.

In sum, we found that it was easier to switch to the weaker task and that it was easier to switch among objects when the task was easier (particularly for the external locus).

\section{Individual Differences: Correlations}

Analysis strategy and tests. For switching attention to be a meaningful construct, switching costs should be correlated across different types of switching (e.g., across judgment types and loci). Significant correlations across different types (e.g., internal switching to shape judgments vs. external shifting to orientation judgments) would suggest that common processes underlie even relatively diverse types of shifting attention, whereas null findings would provide evidence that switching costs involve different processes, depending on where the stimuli are represented and what task is performed. We also tested whether holding locus and judgment type constant would increase the magnitude of correlations among switch costs. If correlations between two external switch costs are greater than those across external/internal, for example, there are likely to be some mental processes that are unique to internal and external shifting. The same argument applies for correlations within versus across judgment types. Significance tests on these hypotheses are perhaps most easily performed using pattern hypothesis testing on the correlation matrices (Steiger, 1980, 2005), which we employed here.

We analyzed switch costs for attribute switching in J2, object switching during the cue period, and object switching during $\mathrm{J} 2$ in separate analyses. Within each switch type (attribute-J2, object-J2, and object-cue), we calculated four separate switch costs, each derived from separate trials: shape judgment/external locus (shE), shape judgment/ internal locus (shI), orientation judgment/external locus (orE), and orientation judgment/internal locus (orI). We assessed intercorrelations among these four switch types. ${ }^{1}$ Attribute switch costs included task preparation and residual switch costs. J2 object switch costs are largely residual costs after preparation has been completed and allow us to test whether residual switch costs are correlated across types. Object switch costs during the cue period reflect a combination of preparatory switch costs and strategic slowing in preparation for efficient performance in J2.

Individual differences in overall and relative speed can artificially inflate correlations in a manner unrelated to whether the switching processes themselves are correlated (e.g., Salthouse et al., 1998). Thus, the analysis proceeded in two stages. First, we assessed whether each switch cost could be predicted by overall speed of processing and by relative speed of basic shape and orientation judgments (see Table 4). If switch costs are correlated with overall speed, higher switch costs may have little to do with executive processing per se. If switch costs are correlated with relative shape versus orientation speed, high switch costs across different types may result simply from individual biases in attention toward one task or another. Our measure of overall speed was the average of shape and orientation judgment RTs in J1 and, for relative speed, was the difference in RT for [shape - orientation] in J1. ${ }^{2}$ We adjusted switch costs by using the residual switch costs after controlling for overall and relative processing speed. This is an alternative to using an arbitrary scaling 
Table 4

Switch Costs Predicted by Processing Speed

\begin{tabular}{|c|c|c|c|c|c|}
\hline Test & Predictor & Beta & $S E$ & $t$ & $p$ Value \\
\hline \multicolumn{6}{|c|}{ Attribute Switching in $\mathrm{J} 2$} \\
\hline \multirow[t]{2}{*}{$\operatorname{shE}$} & Overall speed & .312 & .064 & $4.91^{*}$ & .0000 \\
\hline & Sh - or speed & .000 & .064 & 0.00 & .9965 \\
\hline \multirow[t]{2}{*}{$\operatorname{shI}$} & Overall speed & .241 & .064 & $3.76^{*}$ & .0002 \\
\hline & $\mathrm{Sh}-$ or speed & -.095 & .064 & -1.48 & .1400 \\
\hline \multirow[t]{2}{*}{ orE } & Overall speed & .213 & .063 & $3.38^{*}$ & .0008 \\
\hline & $\mathrm{Sh}-$ or speed & -.217 & .063 & $-3.46^{*}$ & .0006 \\
\hline \multirow[t]{2}{*}{ orI } & Overall speed & .389 & .054 & $7.26^{*}$ & .0000 \\
\hline & Sh - or speed & -.354 & .054 & $-6.61^{*}$ & .0000 \\
\hline \multicolumn{6}{|c|}{ Object Switching in J2 (Residual) } \\
\hline \multirow[t]{2}{*}{$\operatorname{shE}$} & Overall speed & .066 & .067 & 0.99 & .3220 \\
\hline & $\mathrm{Sh}-$ or speed & .060 & .067 & 0.90 & .3689 \\
\hline \multirow[t]{2}{*}{$\operatorname{shI}$} & Overall speed & .098 & .066 & 1.48 & .1406 \\
\hline & Sh - or speed & .099 & .066 & 1.50 & .1360 \\
\hline \multirow[t]{2}{*}{ orE } & Overall speed & .139 & .066 & $2.11^{*}$ & .0358 \\
\hline & $\mathrm{Sh}-$ or speed & -.081 & & -1.23 & .2186 \\
\hline \multirow[t]{2}{*}{ orI } & Overall speed & .035 & & 0.52 & .6027 \\
\hline & Sh - or speed & .088 & .067 & 1.31 & .1907 \\
\hline \multicolumn{6}{|c|}{ Object Switching in Cue Period } \\
\hline \multirow[t]{2}{*}{$\operatorname{shE}$} & Overall speed & -.480 & .060 & $-8.11^{*}$ & .0000 \\
\hline & $\mathrm{Sh}-$ or speed & -.050 & .060 & -0.81 & .4214 \\
\hline \multirow[t]{2}{*}{$\operatorname{shI}$} & Overall speed & -.450 & .060 & $-7.49^{*}$ & .0000 \\
\hline & $\mathrm{Sh}-$ or speed & -.030 & .060 & -0.56 & .5773 \\
\hline \multirow[t]{2}{*}{ orE } & Overall speed & -.510 & .060 & $-8.71^{*}$ & .0000 \\
\hline & Sh - or speed & -.090 & .060 & -1.59 & .1128 \\
\hline \multirow[t]{2}{*}{ orI } & Overall speed & -.360 & .060 & $-5.68^{*}$ & .0000 \\
\hline & Sh - or speed & -.030 & .060 & -0.46 & .6493 \\
\hline
\end{tabular}

Note-Results of multiple regressions predicting each type of switch cost from overall processing speed and relative processing speed [shape - orientation] in J1. Betas are standardized so that values reflect partial correlations between predictors and switch costs. Positive betas indicate higher switch costs with slower overall processing or relatively faster shape than orientation judgments (i.e., a larger asymmetry in switch costs). Error $d f \mathrm{~s}$ were 246 for all tests. I, internal locus; E, external locus; sh, shape judgment task; or, orientation judgment task; J2, second judgment period. ${ }^{*} p<.05$.

method - for example, dividing switch costs by no-switch RT. Whereas the fixed scaling method assumes a fixed ratio of switch costs to overall RT, which may or may not be correct, in our method this relationship is estimated using one free parameter.

We then performed correlation analyses on the adjusted switch costs (see Table 5). We used pattern hypothesis testing in WBCORR (Within-Between Correlational Tests software; Steiger, 2005) to test five a priori hypotheses on the correlation matrices for each switch cost (attribute, residual object, and cue object; see Table 6). Pattern hypothesis testing allows the analyst to specify a pattern of free and fixed correlation estimates and constraints on equality of correlation estimates. For Tests 1 and 2, two-stage generalized least squares was used to estimate correlations and standard errors, and chi-square goodness-of-fit tests were used to assess whether constrained models provided a significantly poorer fit to the correlation matrices, as is common in structural equation modeling. Tests 3-5 were planned contrasts across pairs of correlations, accounting for the covariance among correlation estimates, using $Z$ tests. The hypothesis for each test is explained, along with the results, below.
Effects of overall and relative speed. We first tested whether shift-cost asymmetries were correlated with relative processing speed on the tasks. Relative speed ([sh - or] in J1) was related to switch cost asymmetries for external and internal attribute switching [partial correlation $(p r)=.21, p=.002$, and $p r=.31, p=.0001$, respectively]. Thus, the participants who were faster at the shape task had less difficulty switching to the shape task (and more difficulty shifting away from shape), paralleling the finding of lower switch costs switching to the easier task. For other periods (object-J2 and object-cue), relative speed did not predict asymmetries.

We next entered overall and relative speed as predictors of each type of switch cost in multiple regression, predicting shifts costs in this case, rather than asymmetries. Regression coefficients (standardized to so that betas are partial correlations) and statistics are shown in Table 4.

Effects of overall speed on switch costs. For attribute switch costs in J2, overall speed was strongly predictive of switch costs in each switch type (shE, shI, orE, and orI; all $p r \mathrm{~s} \geq .21$, all $p \mathrm{~s}<.001$; Table 4). Betas were positive, indicating larger switch costs for the participants who were slower overall in J1. Thus, the slower participants showed higher switch costs. Correlations between basic speed and residual object switching (object-J2) were generally nonsignificant. OrE was significantly predicted by overall speed $(p r=.14, p<.05)$, but this effect was much smaller than the others reported here. For object switch costs in the cue period (preparatory costs), there were strong relationships between overall speed and switch costs in each switch type (all $p r$ at least $-.36, p<.0001$ ). Negative betas indicated that the slower participants took less time to prepare object shifts in the cue period, perhaps reflecting a lack of strategic preparation. In sum, the slower participants showed higher switch costs when the switch involved task set preparation, as well as a tendency to prepare less completely in advance.

Effects of relative speed on switch costs. Expanding on the findings on asymmetry above, relative speed [sh - or] predicted time to shift to the more difficult orientation task $(p r=-.22, p<.001$, for orE; and $p r=$ $-.35, p<.0001$, for orI, for attribute-J2). Significant negative betas indicated that the participants with relatively slow orientation processing showed higher switch costs when switching to orientation. Relative speed did not significantly predict switch costs when there was a switch to shape (shE and shI) or object switch costs in either the cue or the $\mathrm{J} 2$ periods (see Table 4).

Correlations among switch costs. Table 5 shows correlations among the four shift costs for raw data (left side) and residuals after controlling for overall and relative speed (right side). All analyses were performed on the adjusted correlation matrices. Pattern hypothesis tests on the adjusted correlation matrices were used to test whether switch costs were correlated across variations in locus (external/internal) and judgment type (shape/orientation) and to assess the impact of these variables on correlation strength. The five planned tests on each correlation matrix are listed as Tests $1-5$ in Table 6. 
Table 5

Correlations Among Switch Costs

\begin{tabular}{|c|c|c|c|c|c|c|c|}
\hline & \multicolumn{3}{|c|}{ Raw Correlations } & \multicolumn{4}{|c|}{$\begin{array}{l}\text { Controlling for Overall } \\
\text { and Relative Speed }\end{array}$} \\
\hline \multicolumn{4}{|c|}{ Attribute Switching in J2 } & \multicolumn{4}{|c|}{ Attribute Switching in J2 } \\
\hline & $\operatorname{shE}$ & $\operatorname{shI}$ & orE & & $\operatorname{shE}$ & $\operatorname{shI}$ & orE \\
\hline shE & - & & & $\operatorname{shE}$ & - & & \\
\hline shI & $.269^{*}$ & - & & shI & $.203^{*}$ & - & \\
\hline orE & $.357^{*}$ & $.330^{*}$ & - & orE & $.303^{*}$ & $.262^{*}$ & - \\
\hline orI & $.287^{*}$ & $.442^{*}$ & $.486^{*}$ & orI & $.173^{*}$ & $.362^{*}$ & $.371^{*}$ \\
\hline \multicolumn{4}{|c|}{ Object Switching in J2 (Residual) } & \multicolumn{4}{|c|}{ Object Switching in J2 (Residual) } \\
\hline & $\operatorname{shE}$ & $\operatorname{shI}$ & orE & & $\operatorname{shE}$ & $\operatorname{shI}$ & orE \\
\hline $\operatorname{sh} E$ & - & & & $\operatorname{shE}$ & - & & \\
\hline $\operatorname{shI}$ & $.182^{*}$ & - & & $\operatorname{shI}$ & $.175^{*}$ & - & \\
\hline orE & $.246^{*}$ & .104 & - & orE & $.247^{*}$ & .102 & - \\
\hline orI & .075 & $.308^{*}$ & $.198^{*}$ & orI & .070 & $.303^{*}$ & $.207^{*}$ \\
\hline \multicolumn{4}{|c|}{ Object Switching in Cue Period } & \multicolumn{4}{|c|}{ Object Switching in Cue Period } \\
\hline & $\operatorname{shE}$ & shI & orE & & $\mathrm{shE}$ & $\operatorname{shI}$ & orE \\
\hline shE & - & & & shE & - & & \\
\hline shI & $.713^{*}$ & - & & shI & $.639^{*}$ & - & \\
\hline orE & $.854^{*}$ & $.678^{*}$ & - & orE & $.812^{*}$ & $.592^{*}$ & - \\
\hline \multirow[t]{7}{*}{ orI } & $.712^{*}$ & $.754^{*}$ & $.649^{*}$ & orI & $.663^{*}$ & $.714^{*}$ & $.587^{*}$ \\
\hline & & & & \multicolumn{4}{|c|}{$\begin{array}{c}\text { Codes for } \\
\text { Pattern Hypothesis Tests }\end{array}$} \\
\hline & & & & & $\operatorname{shE}$ & shI & orE \\
\hline & & & & $\operatorname{shE}$ & & & \\
\hline & & & & shI & $\mathrm{a}$ & & \\
\hline & & & & orE & b & d & \\
\hline & & & & orI & $\mathrm{c}$ & e & $\mathrm{f}$ \\
\hline
\end{tabular}

Note-Correlations among switching costs, raw (left) and after removing linear effects of overall speed and relative shape - orientation judgment speed (right). Adjusted correlations were used in pattern hypothesis tests. I, internal locus; E, external locus; sh, shape judgment task; or, orientation judgment task; J2, second judgment period. The letters a-f are used to describe pattern hypothesis tests. Correlations $\mathrm{c}$ and $\mathrm{d}$ vary both locus and judgment type; $\mathrm{b}$ and e vary judgment type alone; and a and f vary locus alone. ${ }^{*} p<.05$.

We first tested whether all correlations (among shE, shI, orE, and orI) were equal by fitting a single parameter for all the correlation values and performing a goodnessof-fit test (Test 1 in Table 6). A failure to reject the null in this case would indicate that the equal-correlation model is plausible, whereas a rejection would indicate that variations in internal/external locus and shape/orientation judgment type significantly affect correlations and that individual differences in different types of shifting probably reflect locus- and task-specific processes. The null hypothesis was rejected for each type of switching: $\left[\chi^{2}(5)=\right.$ $12.79, p<.05$ for attribute switching, $\chi^{2}(5)=14.08, p<$ .05 for $\mathrm{J} 2$ object switching, and $\chi^{2}(5)=71.8, p<.0001$ for object cue shifting].

We next tested whether there was any significant correlation when both locus and judgment type were varied (Test 2). We did this by setting parameter estimates for correlations between shI-orE and shE-orI to zero, fitting a separate free parameter to each of the other correlations, and performing a goodness-of-fit test on this model. A rejection in this case indicates that the critical correlations are nonzero. For attribute switching, we rejected the null hypothesis that the correlations $r$ (orI, shE) and $r$ (orE, shI) were equal to zero $\left[\chi^{2}(2)=21.0, p<.0001\right]$. For J2 ob- ject switching, we failed to reject $\left[\chi^{2}(2)=3.44, p>.10\right]$, suggesting that there is not an appreciably large general switching ability in residual object switch costs. Notably, the cue shift costs were much more strongly correlated than the residual shift costs, with highly significant crosstask correlations $\left[\chi^{2}(2)=113, p<.000\right]$. Since cue period correlations could reflect strategy choices in deciding how completely to prepare, as well as preparatory shift costs, the strong cue period correlations suggest that the tendency to prepare is more stable across tasks than are shift costs.

We next tested whether correlations on switch costs when locus was held constant but judgment type was varied (Correlations b and e in Table 5) were significantly greater than those with both locus and judgment type varied (Correlations $\mathrm{c}$ and d, Test 3 in Table 6). This is a test of whether there are processes unique to internal and external switching. If there are, varying locus should decrease the strength of the cross-task correlations. This test was significant in each switching type, with average increases in correlation values of $.12, .19$, and .14 for attribute, residual object, and cue object switching, respectively. The statistics are shown in Table 6, including parameter estimates for pairs of correlations, the contrast estimate - that is, $(b+e)-(c+d)$ - and test statistics.

We also tested whether correlations on switch costs when judgment type was held constant (Correlations a and $f$, varying locus) were greater than correlations obtained when both locus and judgment type were varied (Correlations $\mathrm{c}$ and d, Test 4). For attribute switching and residual object switching, this difference was marginally significant (see Table 6), with estimated increases in correlation values of .07 and .11. Although raw correlations (see Table 5) were not analyzed with pattern hypotheses, they were substantially larger before the effects of relative processing speed were removed, suggesting that systematic differences in switch costs due to judgment type were largely, but perhaps not completely, accounted for by relative processing speed. The test was not significant for cue object switching.

Finally, we compared correlation values when judgment type was held constant (Correlations a and $\mathrm{f}$ in Table 5) with those obtained when locus was held constant (Correlations $\mathrm{b}$ and $\mathrm{e}$ ), to determine which variable had the larger effects on switch costs (Test 5 in Table 6). For attribute and residual object switches, the test was not significant, indicating that neither variable was clearly more important than the other. For cue object switches, locus was the more important variable. Constant locus increased the correlation by .15, in comparison with constant judgment type. Thus, overall, locus emerged as a significant variable in each type of switching, whereas effects of judgment type appear to have been largely accounted for by relative processing speed.

\section{GENERAL DISCUSSION}

Overall, the results provide evidence for both commonalities and separability in the processes engaged in task 
switches across types of tasks. Evidence for common processes comes from correlations in switch costs across tasks, which were significant for switches that involved task set preparation (but not residual switch costs). Evidence that task switches in different tasks involve different processes comes from both correlational and ANOVA results.

When stimuli were maintained in WM (internal locus) versus perceptually available (external locus), switch costs were apparent for both types of task. However, combining RT and accuracy, object switch costs were greater for the external task, and attribute switch costs were greater for the internal task. In addition, overadditive dual-switch costs were found for the internal task, but not for the external task. This result was found despite the fact that the participants had as long as necessary to first complete the object switch. This implies that the ability to first select the object and then select the attribute (e.g., Sternberg, 1969), without interference, is diminished during switching in WM.

Asymmetries in switch costs existed for both loci, so that it was easier to switch to the more salient and more quickly processed attribute (shape). These asymmetries existed for both internal and external tasks, and for both tasks, they were predicted by relative basic processing speed. However, switch cost asymmetries were larger for the external task, consistent with the idea that asymmetries are partially created when visible stimuli prime as- sociated task sets (Wylie \& Allport, 2000). These findings are also consistent with models of task switching in which switch costs are determined by relative task strength (Gilbert \& Shallice, 2002). Such models can produce both the asymmetry pattern we report here and the "paradoxical" switch cost asymmetries observed by Allport et al. (1994) and others (Monsell et al., 2000) but require additional input from a top-down task selection mechanism to produce "paradoxical" asymmetry.

One explanation for why attribute shifting costs and attribute $\times$ object interactions are greater in internal tasks is this: Selecting an object stored in WM may require the selection and rehearsal of object attributes as well. For example, it is impossible to visualize a red square without representing its redness or its squareness. Thus, the attribute selection process may be more difficult in WM, because both relevant and irrelevant attributes are selected along with the object and the potential for interference is greater. By contrast, attribute selection when stimuli are visible can take advantage of visual spatial attention and object-based feature grouping to select objects without fully processing their attributes (e.g., Downing, Liu, \& Kanwisher, 2001; Driver, 1996; Egly, Driver, \& Rafal, 1994; Lamy \& Egeth, 2002; Macaluso, Frith, \& Driver, 2002; O’Craven, Downing, \& Kanwisher, 1999). In support of this view, Vogel, Woodman, and Luck, (2001) found that people can typically store three to four attri-

Table 6

Pattern Hypothesis Tests

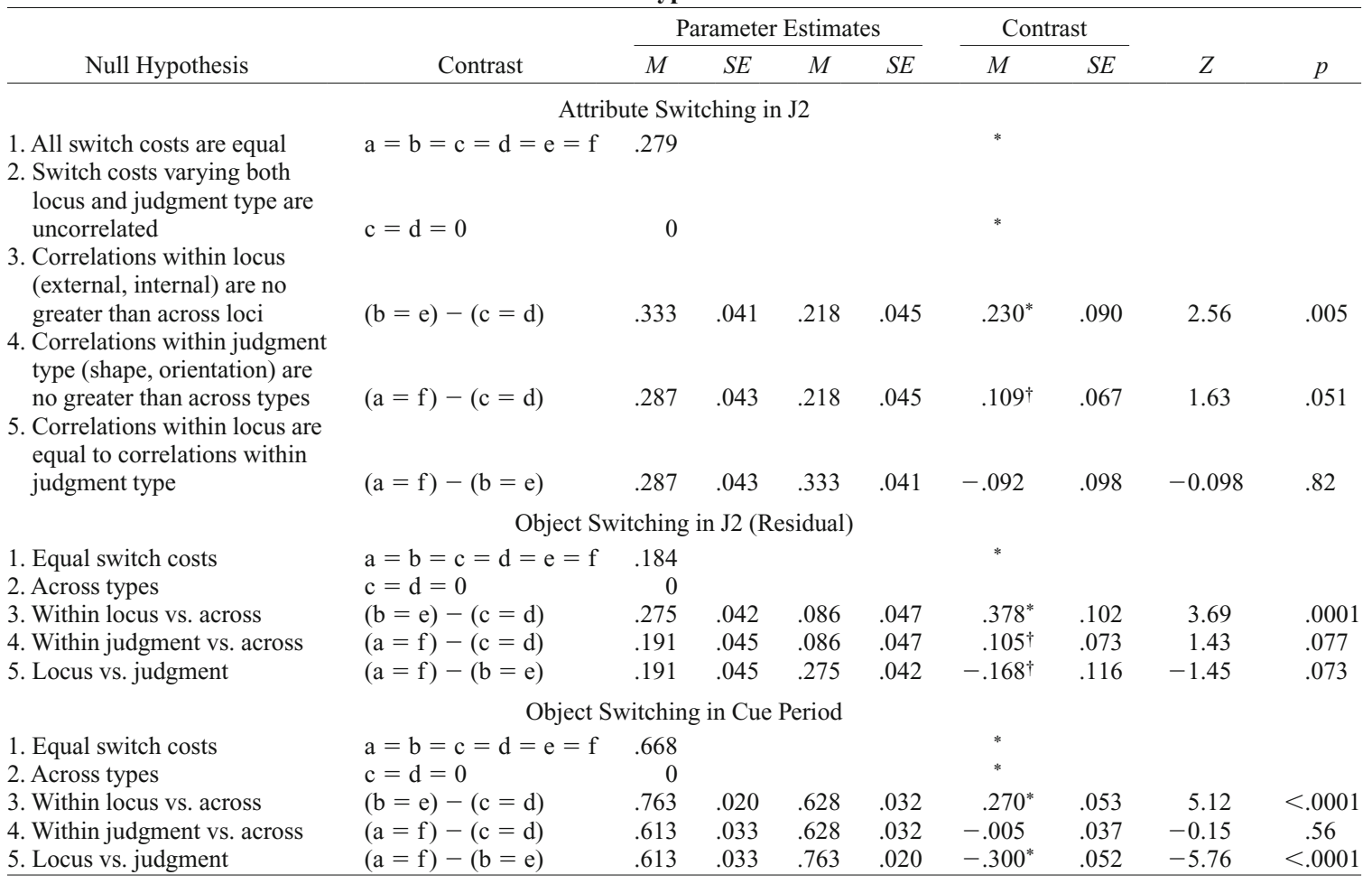

Note-The same five tests were performed on attribute switches, object switches in J2, and object switches in the object cue period. See Table 5 for explanation of letter codes a-f. Equal signs denote correlation estimates constrained to be equal in the model fit. $\quad{ }^{*} p<.05 . \quad \dagger p<.10$, one-tailed. 
butes of objects in WM at a time but that they can store two attributes each of three to four objects, suggesting that objects are units stored in WM and that multiple attributes are bound with object representations. Thus, switching objects stored in WM necessarily makes both the relevant and the irrelevant attributes of the object salient, both increasing attribute shifting times and causing interference with the attribute-switching process when both object and attribute switches are performed together.

By contrast, object switching may create more interference when stimuli are visible, since the incorrect object is also visible and may attract attention. Thus, in external tasks in the literature, visible stimuli that afford both tasks (i.e., bivalent stimuli) produce much greater switch costs (Jersild, 1927). Object selection may be rapid in WM because stimuli are stored and rehearsed object-by-object (Vogel et al., 2001).

\section{Correlational Evidence for Separable Switching Processes}

These data provide indirect support for the idea that locus and judgment type differentially engage controlled retrieval (comparable to the goal selection stage of Rubinstein et al., 2001) and interference resolution (comparable to rule activation) processes. More direct quantitative evidence for the degree of similarity in performance among these different variants of shifting tasks is provided by the individual-differences analyses. Even after controlling for overall processing speed and relative processing speed - which may increase correlations among switching tasks if switch costs are proportional to overall RT or relative task difficulty, as we show here-correlations among tasks were significantly greater within locus (internal or external) than across loci. This result held for attribute switches, which involved both goal selection and rule activation stages, and for both goal selection (preparatory) and rule activation (residual) stages of object switching. Thus, switch costs among visible stimuli and those stored in WM are, at least in part, measures of different abilities.

Two more points are worth noting. First, correlations within judgment type (shape and orientation) were marginally stronger than those across judgment types, suggesting that although controlling for relative speed appears to reduce the influence of judgment-specific switching processes, it does not do so completely. This pattern is consistent with the idea that relative speed is related to relative automaticity (Dyer, 1973) but is not sufficient to completely account for it (MacLeod \& Dunbar, 1988). Second, the preparatory object shift costs in our experiment were self-paced and, so, were influenced by strategy differences. This might explain the very high correlations among object switch costs generally and underscores the point that strategic choices applied consistently across tasks are a major component of switch costs.

However, the larger correlations within internal and external loci, in comparison with across loci, are harder to explain in this manner, and we take it as corroboration of the unique processes involved in internal and external goal shifting.

\section{Correlational Evidence for Common Switching Processes}

Having reviewed this evidence for separate processes for internal and external shifting, we will turn next to the issue of whether switching processes are unique to particular task types or whether evidence for common processes can be found even for the most dissimilar tasks we studied. We found that attribute switch costs were correlated even when the tasks were quite dissimilar, in that they were significant across levels of both locus and judgment type. These switch costs involved both goal selection and rule activation stages. However, residual shift costs (correlations on object switch costs after the goal shift had largely been completed) were uncorrelated. Thus, goal selection seemed to involve common processes across diverse task types, but rule application during residual shifting appeared to involve different cognitive processes for different tasks.

These findings parallel those from an fMRI study conducted recently in 39 participants on the same tasks (Wager et al., 2005). We found that external switching more strongly engaged the extrastriate cortex bilaterally and that internal switching more strongly engaged frontal and parietal (particularly the precuneus) regions associated with switching attention as identified in meta-analyses (Derrfuss, Brass, Neumann, \& von Cramon, 2005; Wager, Jonides, \& Reading, 2004). The regions more activated in internal switches have been implicated in executive control of WM more generally (Wager \& Smith, 2003), suggesting a relationship between switching and manipulation of information in WM. One of these regions, the inferior frontal junction, has been related specifically to controlled updating of WM (Derrfuss et al., 2005). Although this is evidence for the separability of different kinds of task switching, we (Wager et al., 2005) found that although the magnitude of switching activations in these regions varied across tasks, each of these regions was still activated in shift-no-shift comparisons in all the tasks. This finding suggests that basic attentional control processes are involved in each type of shift but that the degree to which they are required varies with task condition.

\section{Relation of Switching to Other Cognitive Abilities}

Unlike other studies that have focused on relating switch costs to other cognitive ability measures, we focused exclusively on the taxonomy of processes within switching tasks. However, other studies have shown that switching costs are related to other cognitive control processes. Miyake et al. (2000), for example, tested participants on three different switching tasks. Using confirmatory factor analysis, they found that switching costs were moderately intercorrelated and were also moderately related to constructs of response inhibition and monitoring of information in WM. Ward et al. (2001) also investigated the relationship among two similar switching tasks and two Stroop tasks and found that switching tasks were moderately correlated. However, that study was limited in its ability to relate switching to inhibition by low correlations between the two versions of the Stroop tasks. Salthouse 
et al. (1998) also identified a switching construct that was related to but dissociable from basic processing speed, as we found here. They found a relationship between the switching construct and a higher cognition factor composed of more complex problem-solving tasks, but this relationship was largely explained by common influences of basic processing speed on both switching and higher cognition. However, Salthouse et al. used three very similar switching tasks: All involved making judgments on visually available digits. Thus, although this choice of tasks was advantageous in producing a stronger switching factor in that experiment than in Miyake et al. (2000), the "switching" construct in Salthouse et al. may not be representative of task switching in general. Perhaps, as is suggested by neuroimaging evidence for co-localization of switching and other executive control operations, complex measures of problem solving are more closely related to control of attention within WM than to the efficiency of perceptual shifting mechanisms.

This leaves us with three general points. First, basic processing speed and relative speed appear to influence measured switch costs, and these effects should be controlled for when examining correlations among switching tasks. Second, different switching tasks involve different processes and are, thus, likely to involve different brain mechanisms and relate to different processes. In particular, switching within WM is separable from switching in perception. Finally, individual-differences analyses are an informative way to develop models of the structure of human performance. Understanding how elementary control processes are grouped is essential for identifying the building blocks of cognitive abilities and developing the right constructs on which to test for selective impairments.

\section{REFERENCES}

Allport, D. A., Styles, E. A., \& Hsieh, S. (1994). Shifting intentional set: Exploring the dynamic control of tasks. In C. Umiltà \& M. Moscovitch (Eds.), Attention and performance $X V$ : Conscious and nonconscious information processing (pp. 421-452). Cambridge, MA: MIT Press, Bradford Books.

Allport, [D.] A., \& Wylie, G. (1999). Task-switching: Positive and negative priming of task-set. In G. W. Humphreys, J. Duncan, \& A. Treisman (Eds.), Attention, space, and action: Studies in cognitive neuroscience (pp. 273-296). Oxford: Oxford University Press.

BAdDEley, A. (1992). Working memory. Science, 255, 556-559.

Bleckley, M., Durso, F. T., Crutchfield, J. M., Engle, R. W., \& Khanna, M. M. (2003). Individual differences in working memory capacity predict visual attention allocation. Psychonomic Bulletin \& Review, 10, 884-889.

Burgess, P. W., Alderman, N., Evans, J., Emslie, H., \& Wilson, B. A. (1998). The ecological validity of tests of executive function. Journal of the International Neuropsychological Society, 4, 547-558.

CONWAY, A. R. A., KanE, M. J., \& ENGLE, R. W. (2003). Working memory capacity and its relation to general intelligence. Trends in Cognitive Sciences, 7, 547-552.

Coull, J. T., Frith, C. D., Büchel, C., \& Nobre, A. C. (2000). Orienting attention in time: Behavioural and neuroanatomical distinction between exogenous and endogenous shifts. Neuropsychologia, 38, 808-819.

Derrfuss, J., Brass, M., Neumann, J., \& von Cramon, D. Y. (2005). Involvement of the inferior frontal junction in cognitive control: Metaanalyses of switching and Stroop studies. Human Brain Mapping, 25, 22-34.

DoWNING, P., LIU, J., \& KANWISHER, N. (2001). Testing cognitive mod- els of visual attention with fMRI and MEG. Neuropsychologia, 39, 1329-1342.

Dreher, J. C., Koechlin, E., Ali, S. O., \& Grafman, J. (2002). The roles of timing and task order during task switching. Neurolmage, 17, 95-109.

DrIVER, J. (1996). Attention and segmentation. The Psychologist, 9 , 119-123.

Duncan, J., Emslie, H., Williams, P., Johnson, R., \& Freer, C. (1996). Intelligence and the frontal lobe: The organization of goaldirected behavior. Cognitive Psychology, 30, 257-303.

Duncan, J., Johnson, R., Swales, M., \& Freer, C. (1997). Frontal lobe deficits after head injury: Unity and diversity of function. Cognitive Neuropsychology, 14, 713-741.

DYER, F. N. (1973). The Stroop phenomenon and its use in the study of perceptual, cognitive, and response processes. Memory \& Cognition, 1, 106-120.

Egly, R., Driver, J., \& Rafal, R. D. (1994). Shifting visual attention between objects and locations: Evidence from normal and parietal lesion subjects. Journal of Experimental Psychology: General, 123, $161-177$

GARAVAN, H. (1998). Serial attention within working memory. Memory \& Cognition, 26, 263-276.

Garavan, H., Ross, T. J., LI, S.-J., \& Stein, E. A. (2000). A parametric manipulation of central executive functioning. Cerebral Cortex, 10, 585-592.

Gilbert, S. J., \& Shallice, T. (2002). Task switching: A PDP model. Cognitive Psychology, 44, 297-337.

GOPHER, D. (1996). Attention control: Explorations of the work of an executive controller. Cognitive Brain Research, 5, 23-38.

Gopher, D., Armony, L., \& GreEnSHPAN, Y. (2000). Switching tasks and attention policies. Journal of Experimental Psychology: General, 129, 308-339.

HiTCH, G. J., \& BADDELEY, A. D. (1976). Verbal reasoning and working memory. Quarterly Journal of Experimental Psychology, 28, 603-621.

Hsieh, S., \& Allport, A. (1994). Shifting attention in a rapid visual search paradigm. Perceptual \& Motor Skills, 79, 315-335.

JERSILD, A. (1927). Mental set and shift. Archives of Psychology, Whole No. 89, 5-82.

Johnson, R. A., \& Wichern, D. W. (2002). Applied multivariate statistical analysis (5th ed.). Upper Saddle River, NJ: Prentice Hall.

KAne, M. J., \& Engle, R. W. (2003). Working-memory capacity and the control of attention: The contributions of goal neglect, response competition, and task set to Stroop interference. Journal of Experimental Psychology: General, 132, 47-70.

Kane, M. J., Hambrick, D. Z., Tuholski, S. W., Wilhelm, O., Payne, T. W., \& ENGLE, R. W. (2004). The generality of working memory capacity: A latent-variable approach to verbal and visuospatial memory span and reasoning. Journal of Experimental Psychology: General, 133, 189-217.

KimberG, D. Y., Aguirre, G. K., \& D’Esposito, M. (2000). Modulation of task-related neural activity in task-switching: An fMRI study. Cognitive Brain Research, 10, 189-196.

$\mathrm{KoCH}$, I. (2003). The role of external cues for endogenous advance reconfiguration in task switching. Psychonomic Bulletin \& Review, 10, 488-492.

LAMY, D., \& EgETh, H. (2002). Object-based selection: The role of attentional shifts. Perception \& Psychophysics, 64, 52-66.

Macaluso, E., Frith, C. D., \& Driver, J. (2002). Directing attention to locations and to sensory modalities: Multiple levels of selective processing revealed with PET. Cerebral Cortex, 12, 357-368.

MacLeod, C. M., \& Dunbar, K. (1988). Training and Stroop-like interference: Evidence for a continuum of automaticity. Journal of Experimental Psychology: Learning, Memory, \& Cognition, 14, 126-135.

MAYR, U. (2003). Towards principles of executive control: How mental sets are selected. In R. H. Kluwe, G. Lüer, \& F. Rösler (Eds.), Principles of learning and memory (pp. 223-241). Basel: Birkhäuser.

MaYR, U., \& KLIEGL, R. (2000). Task-set switching and long-term memory retrieval. Journal of Experimental Psychology: Learning, Memory, \& Cognition, 26, 1124-1140.

MEIRAN, N. (1996). Reconfiguration of processing mode prior to task performance. Journal of Experimental Psychology: Learning, Memory, \& Cognition, 22, 1423-1442. 
Meiran, N., Chorev, Z., \& SAPIR, A. (2000). Component processes in task switching. Cognitive Psychology, 41, 211-253.

Meiran, N., Hommel, B., BIBI, U., \& LeV, I. (2002). Consciousness and control in task switching. Consciousness \& Cognition, 11, 10-33.

Miller, E. K., \& CoHEN, J. D. (2001). An integrative theory of prefrontal cortex function. Annual Review of Neuroscience, 24, 167-202.

Miyake, A., Friedman, N. P., Emerson, M. J., Witzki, A. H., Howerter, A., \& Wager, T. D. (2000). The unity and diversity of executive functions and their contributions to complex "frontal lobe" tasks: A latent variable analysis. Cognitive Psychology, 41, 49-100.

Monsell, S., Yeung, N., \& Azuma, R. (2000). Reconfiguration of task-set: Is it easier to switch to the weaker task? Psychological Research, 63, 250-264.

NoRMAN, D. A., \& SHALlice, T. (1986). Attention to action: Willed and automatic control of behavior. In R. J. Davidson, G. E. Schwartz, \& D. Shapiro (Eds.), Consciousness and self-regulation (Vol. 4, pp. 118). New York: Plenum.

O'Craven, K. M., Downing, P. E., \& Kanwisher, N. (1999). fMRI evidence for objects as the units of attentional selection. Nature, 401, 584-587.

OWen, A. M., Roberts, A. C., Polkey, C. E., Sahakian, B. J., \& RobBINS, T. W. (1991). Extra-dimensional versus intra-dimensional set shifting performance following frontal lobe excisions, temporal lobe excisions or amygdalo-hippocampectomy in man. Neuropsychologia, 29, 993-1006.

PACHELLA, R. G. (1974). The interpretation of reaction time in information processing research. In B. H. Kantowitz (Ed.), Human information processing: Tutorials in performance and cognition (pp. 41-82). Hillsdale, NJ: Erlbaum.

Rabbitt, P., \& Lowe, C. (2000). Patterns of cognitive ageing. Psychological Research, 63, 308-316.

RoBERTS, A. C., \& WALLIS, J. D. (2000). Inhibitory control and affective processing in the prefrontal cortex: Neuropsychological studies in the common marmoset. Cerebral Cortex, 10, 252-262.

Rogers, R. D., \& Monsell, S. (1995). Costs of a predictable switch between simple cognitive tasks. Journal of Experimental Psychology: General, 124, 207-231.

RousSEEUW, P. J. (1984). Least median of squares regression. Journal of the American Statistical Association, 79, 871-881.

Rubinstein, J. S., MEYER, D. E., \& Evans, J. E. (2001). Executive control of cognitive processes in task switching. Journal of Experimental Psychology: Human Perception \& Performance, 27, 763-797.

SALTHOUSE, T. A. (1996). The processing-speed theory of adult age differences in cognition. Psychological Review, 103, 403-428.

Salthouse, T. A., Fristoe, N., McGuthry, K. E., \& Hambrick, D. Z. (1998). Relation of task switching to speed, age, and fluid intelligence. Psychology \& Aging, 13, 445-461.

SHAFIULLAH, M., \& MONSELL, S. (1999). The cost of switching between Kanji and Kana while reading Japanese. Language \& Cognitive Processes, 14, 567-607.

SPECTOR, A., \& BIEDERMAN, I. (1976). Mental set and mental shift revisited. American Journal of Psychology, 89, 669-679.
Steiger, J. H. (1980). Testing pattern hypotheses on correlation matrices: Alternative statistics and some empirical results. Multivariate Behavioral Research, 15, 335-352.

Steiger, J. H. (2005). Comparing correlations: Pattern hypothesis tests between and/or within independent samples. In A. Maydeu-Olivares \& J. J. McArdle (Eds.), Contemporary psychometrics: A festschrift for Roderick P. McDonald (pp. 377-414). Mahwah, NJ: Erlbaum.

STERnBerg, S. (1969). The discovery of processing stages: Extensions of Donders' method. In W. G. Koster (Ed.), Attention and performance II (pp. 276-315). Amsterdam: North-Holland.

Sylvester, C. Y. C., Wager, T. D., Lacey, S. C., Hernandez, L., Nichols, T. E., Smith, E. E., \& Jonides, J. (2003). Switching attention and resolving interference: fMRI measures of executive functions. Neuropsychologia, 41, 357-370.

Vogel, E. K., Woodman, G. F., \& LUCK, S. J. (2001). Storage of features, conjunctions, and objects in visual working memory. Journal of Experimental Psychology: Human Perception \& Performance, 27, 92-114.

WAGER, T. D., Jonides, J., \& REAdING, S. (2004). Neuroimaging studies of shifting attention: A meta-analysis. NeuroImage, 22, 1679-1693.

Wager, T. D., Jonides, J., SMith, E. E., \& Nichols, T. E. (2005). Toward a taxonomy of attention shifting: Individual differences in fMRI during multiple shift types. Cognitive, Affective, \& Behavioral Neuroscience, $\mathbf{5}, 127-143$.

WAGER, T. D., \& SMITH, E. E. (2003). Neuroimaging studies of working memory: A meta-analysis. Cognitive, Affective, \& Behavioral Neuroscience, 3, 255-274.

WARD, G., RoBerTs, M. J., \& PhILliPs, L. H. (2001). Task-switching costs, Stroop-costs, and executive control: A correlational study. Quarterly Journal of Experimental Psychology, 54A, 491-511.

Wylie, G., \& AllPORT, A. (2000). Task switching and the measurement of "switch costs." Psychological Research, 63, 212-233.

Yeung, N., \& MonSELL, S. (2003a). The effects of recent practice on task switching. Journal of Experimental Psychology: Human Perception \& Performance, 29, 919-936.

YeUnG, N., \& MONSELL, S. (2003b). Switching between tasks of unequal familiarity: The role of stimulus-attribute and response-set selection. Journal of Experimental Psychology: Human Perception \& Performance, 29, 455-469.

\section{NOTES}

1. Attribute and object switches involve the same trials, so are not independent; thus, correlating attribute with object switch costs is problematic.

2. J1 and J2 speed measures were correlated $(r=.91)$, but we used J1 for speed measures, because RTs for that period are independent from those used to calculate switch costs in J2.

(Manuscript received September 16, 2004; revision accepted for publication September 5, 2005.) 